\title{
PEPTIC ULCER IN THE BRITISH ARMY: A COMPARISON OF OUTCOME FOLLOWING MEDICAL AND EARLY OR LATE SURGICAL TREATMENT IN THE PRE-CIMETIDINE ERA
}

\author{
COL D M ROBERTS, MD, FRCP(Ed), MRCP(Lond) \\ LT COL D O H MESSENT, MB, FRCS* \\ Royal Army Medical College, Millbank
}

It is difficult to define the "best" treatment for peptic ulcer because the effectiveness of treatment may be measured in many different ways, each affecting the "outcome". Therapeutic objectives might include relief of symptoms, healing of ulcer, prevention of complications, prevention of relapses, and social or occupational rehabilitation. Despite the multiplicity of objectives, most clinicians will have some concept of what constitutes an acceptable or an unacceptable "outcome" of treatment for each patient.

In the British Army, compared with civilian life, certain criteria require to be more heavily emphasised than others in considering outcome. Fitness to perform his duties efficiently and continuously is a sine qua non of a serviceman's employment. If a medical defect exists which actually or potentially restricts his employability he must be either invalided from the service or medically downgraded; the latter may render him ineligible for consideration for promotion and thereby ruin his career. Because he is expensive to train a new recruit will be more readily invalided from the service than a mature, fully-trained specialist, the loss of whom would be a more catastrophic event both for the service and for the individual.

Although only a small proportion of servicemen with peptic ulcer are invalided, this disease remains the single most common cause of invaliding from the British Army (Statistical Report on the Health of the Army, 1975). This fact is well known to service olinicians but despite this there is no unanimity as to the "best" approach to management, nor to the difficult question of the degree of medical downgrading or restriction upon employability indicated for peptic ulcer patients in various circumstances. Any data which throw light upon this problem are useful.

This paper presents a retrospective analysis of the outcome of medical versus surgical treatment for peptic ulcer in a cohort of serving personnel in the pre-Cimetidine era.

\section{Patients and methods}

All personnel serving in the British Army who were first diagnosed during the year 1965, as having a peptic ulcer were identified and their medical documents examined. Reports of all out-patient attendances, hospital admissions, 
routine medical examinations and Medical Board Proceedings from the time of diagnosis until either the time of discharge from the Army or the present day were available for perusal.

Only cases in which the diagnosis was established at operation or by unequivocal radiological findings were considered. Endoscopy was not in general use at that time. There were 155 such patients, all but two of them male, ranging from 17 to 52 years, mean 29.7 years. A total of 145 patients had a duodenal or pre-pyloric ulcer, seven had a gastric ulcer and three had both a duodenal and a gastric ulcer.

Four categories of treatment were identified:

1. "Initial treatment medical": when, following diagnosis, treatment was initially by diet and medication during a stay in hospital of three weeks or more (135 cases. Age range 17-49 years, mean 29.5 years).

2. "Initial treatment repair of perforation": when initial presentation was by perforation of the ulcer and this was treated by early surgical repair $(11$ cases. Age range 17-35 years, mean 24.6 years).

3. "Subsequent treatment surgical": when, following an initial spell of inpatient medical treatment and a subsequent interval of at least three months, definitive surgical treatment was later undertaken (44 cases. Age range 23-52 years, mean 35.6 years).

4. "Initial treatment surgical, excluding repair of perforation": when definitive surgical treatment was undertaken at the time of initial presentation and diagnosis and, in any case within a month. (Nine cases. Age range 26-50 years, mean 38.3 years).

A total of 65 operations were performed on the patients in this survey. Surgical operations performed at the time of initial presentation (other than repair of perforation) comprised seven partial gastrectomies, two vagotomy plus drainage, and one vagotomy, drainage and excision of gastric ulcer. Surgical operations undertaken after a period of failed medical treatment comprised 34 vagotomy plus drainage, seven partial gastrectomies, one antrectomy, two vagotomy plus partial gastrectomy, and one repair of perforation.

Duration of follow-up for each case was measured from the time of administration of the treatment in question until the time of the last recorded medical report or, in some cases treated medically, until subsequent surgery. The last recorded medical report often coincided with the time of discharge from the Army although in some cases the individual was known to be still serving and symptom-free.

Altogether, 157 patients were followed up over a total of 1,110.5 years, giving an average follow-up period of 7.07 years.

The following parameters having a possible bearing upon "outcome" were among those recorded: age of patient at diagnosis; site of ulcer; complications present at time of diagnosis or occurring subsequently; medical (PULHEEMS) gradings and dates of allocation; proportion of follow-up period which was symptomatic (including symptoms from the complications of surgical treatment such as dumping and diarrhoea as well as dyspepsia); number of hospital 
admissions during the follow-up period, and the rate of promotion during the follow-up period.

Each of the following complications was given equal weighting: haemorrhage, perforation, stenosis, malignancy, anaemia sufficient to warrant specific therapy, diarrhoea severe enough to warrant complaint by the patient, dumping, recurrence of ulcer whether anastomotic or otherwise, and failure to heal of initial ulcer within a period of three months of the initiation of specific treatment. Although the designation of failure to heal as a complication is unconventional it was felt unjustified to omit this in any assessment of the outcome of treatment.

Statistical analysis was by the standard $t$ test (differences between proportions) and a confidence interval of 95 per cent accepted.

\section{Results}

Out of 135 cases initially treated medically, 38 subsequently came to surgery and six others were invalided from the service. Out of 11 cases of perforation initially treated by surgical repair, five subsequently came to surgery and one other was invalided from the service. Out of nine cases initially treated surgically (excluding repair of perforation) none subsequently came again to surgery and one was invalided from the service. Out of 43 cases subsequently treated surgically, two were invalided from the service, two died from unconnected causes and three required further surgery at a later date, one for repair of incisional hernia.

During the follow-up period 10 out of 155 patients were invalided from the service giving an invaliding rate of 0.9 per cent per annum. There was no difference in the invaliding rate between the various treatment groups. During the same follow-up period 65 operations were performed for peptic ulcer or its complications giving a surgery rate of 6.0 per cent per annum.

The outcome in response to various treatments as measured by several parameters is represented in Figure 1. The response to both initial and subsequent surgical treatment was significantly better than the response to initial medical treatment in terms of proportion of follow-up years which were symptomatic, the frequency of subsequent hospital admissions, the incidence of complications and the proportion of follow-up years spent downgraded, but there was no significant difference in the rate of promotion.

The effect of age on the outcome in response to treatments 1 and 3 is shown in Figure 2 which compares patients aged 26 years and under with those aged 33 years and over. Comparison with treatments 2 and 4 is not possible because of the small numbers of patients in these groups. Age has no significant effect on the outcome in response to initial medical treatment expressed as the proportion of follow-up years spent symptomatic, frequency of subsequent hospital admissions, or the incidence of complications, although it was significantly related to the rate of promotion.

In contrast, age had a significant effect on the outcome in response to subsequent surgical treatment as measured by all these parameters. With in- 


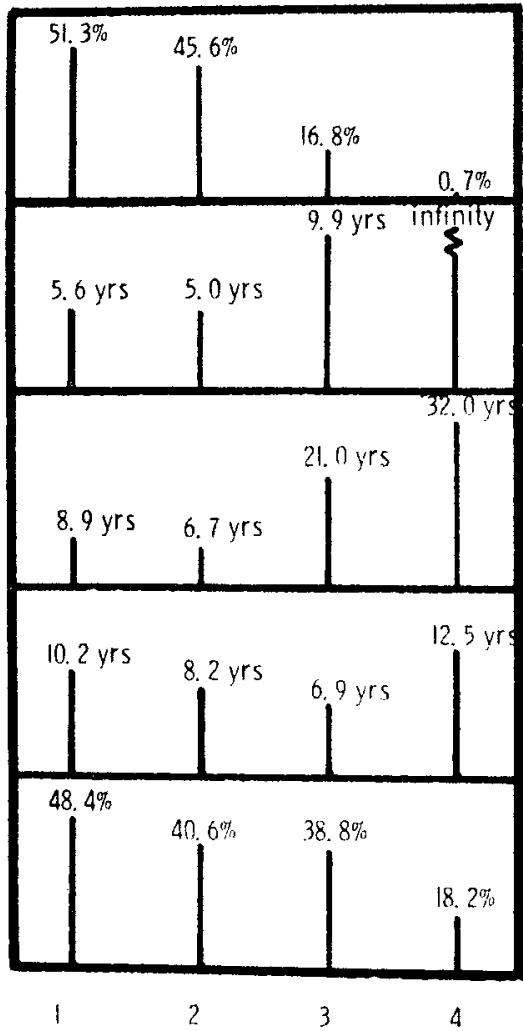

Proportion of follow-up years symptomatic

Mean interval belween subsequent hospita! admissions

Medn interval between complications

Fig. 1. The outcome of peptic ulcer in response to various treatments. Treatment: 1. Initial treatment medical. 2. Initial treatment repair of perforation. 3. Subsequent treatment surgical. Mean intervat between 4. Initial treatment surrank increments gical, excluding repair of perforation.

Proportion of tollow-up years medically downgraded

Ireatment

creasing age the outcome was significantly less good in respect of symptoms, admissions and complications.

In both groups-those treated initially medically and in those treated subsequently surgically-those in the younger age group were promoted at a significantly faster rate than those in the older group. This implies that a soldier's rate of promotion during any given period is determined more by his age than by the outcome in response to treatment.

Generally, the patients with a gastric ulcer were slightly older and fared worse than those with a duodenal or pre-pyloric ulcer as regards complications and admissions during the follow-up period but rather better as regards the time spent symptomatic. However, because of the small number of patients with a gastric ulcer these differences were not statistically significant.

\section{Discussion}

The "best" scheme of management for a patient with peptic ulcer in the Army is not necessarily the same as in civilian life and, in any case, will vary from case to case. Nevertheless, the data presented have shown that definitive surgical treatment, whether given at the time of initial diagnosis or at some time later, gives significantly better results than medical treatment as measured 


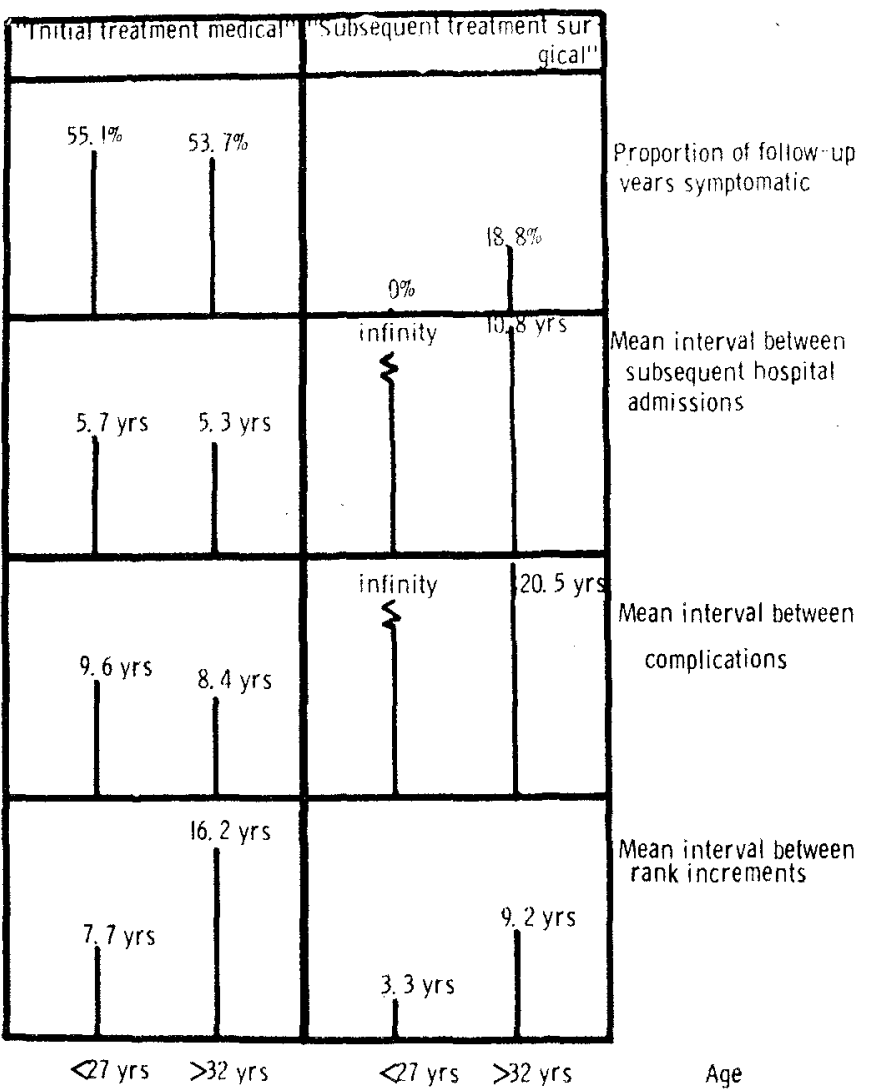

Fig. 2. The effect of age on the outcome in response to initial medical treatment and subsequent surgical treatment.

by several clinical parameters. Apart from these clinical considerations, surgical treatment will also be followed by less interference with a man's career by medical downgrading although it will not enhance his rate of promotion since this is predominantly dependent upon his age and length of service.

The data also show that the results of surgical treatment are better the younger the patient whereas age makes no difference to the outcome of medical treatment.

These facts are contrary to the widely held beliefs that gastric surgery should be "earnt" by a more or less substantial period of symptoms and that it is generally unwise to operate on young people (two myths previously exposed by Small $e t a l^{1}$ ). The average duration of follow-up for the patients reported upon was 7.1 years but the possibility cannot be denied that the long-term adverse effects of surgery might have been more apparent if a longer follow-up had been examined.

To set against this is the probability that it was the more severe cases, which were selected for surgical treatment, the milder cases being treated medically, a likelihood which cannot be verified from the data.

The evidence presented suggests that clinicians should be more willing to 
consider surgery for the treatment of peptic ulcer in the Army and to consider it at an early stage in the patient's career.

It is now established that some 75 per cent of all peptic ulcers will heal after a suitable course of Cimetidine in full dosage ${ }^{2,3}$ and that with maintenance therapy the relapse-rate over one year or so will be reduced ${ }^{4}{ }^{5}$. There is no evidence that Cimetidine is safe when administered over the very long term and hence none that it will influence the overall natural history of the peptic ulcer diathesis.

In the context of the career of the serving man with peptic ulcer, therefore, the conclusions drawn from the data now presented should continue to influence clinicians, although this influence may be modified by longer experience with histamine-2 receptor antagonists.

\section{REFERENCES}

1. Small, W P et al (1969). Peptic ulcer surgery: selection for operating by "earning". Gut 10, 996-1003.

2. BARDHAN, K D et al (1977). The effect of Cimetidine on duodenal ulceration. An interim report of a multicentre double-blind trial. 2nd Int. Symp. Histamine H2-Receptor Antagonists, Excerpta Medica 260, 271.

3. HuNT, $\mathbf{R} \mathbf{H}$ et al (1977). Cimetidine in the treatment of gastric ulcer. 2nd Int. Symp. Histamine H2-Receptor Antagonists. Excerpta Medica 260, 293-296.

4. MACHELL, $R$ J et al (1978). Maintenance Cimetidine in the prevention of gastric ulcer relapse. Gut 19, A442.

5. HeTzeL, D J (1978). Maintenance of remission of duodenal ulcer by Cimetidine: a double-blind controlled trial. Gut 19, A442. 